\title{
Video Article \\ Isolation of Specific Genomic Regions and Identification of Associated Molecules by enChIP
}

\author{
Toshitsugu Fujita ${ }^{1}$, Hodaka Fujii ${ }^{1}$ \\ ${ }^{1}$ Chromatin Biochemistry Research Group, Combined Program on Microbiology and Immunology, Research Institute for Microbial Diseases, Osaka University
}

Correspondence to: Hodaka Fujii at hodaka@biken.osaka-u.ac.jp

URL: https://www.jove.com/video/53478

DOI: doi: $10.3791 / 53478$

Keywords: Molecular Biology, Issue 107, ChIP, chromatin immunoprecipitation, locus-specific ChIP, enChIP, engineered DNA-binding moleculemediated ChIP, chromatin, epigenetics, genome function

Date Published: 1/20/2016

Citation: Fujita, T., Fujii, H. Isolation of Specific Genomic Regions and Identification of Associated Molecules by enChIP. J. Vis. Exp. (107), e53478, doi:10.3791/53478 (2016).

\section{Abstract}

The identification of molecules associated with specific genomic regions of interest is required to understand the mechanisms of regulation of the functions of these regions. To enable the non-biased identification of molecules interacting with a specific genomic region of interest, we recently developed the engineered DNA-binding molecule-mediated chromatin immunoprecipitation (enChIP) technique. Here, we describe how to use enChIP to isolate specific genomic regions and identify the associated proteins and RNAs. First, a genomic region of interest is tagged with a transcription activator-like (TAL) protein or a clustered regularly interspaced short palindromic repeats (CRISPR) complex consisting of a catalytically inactive form of Cas 9 and a guide RNA. Subsequently, the chromatin is crosslinked and fragmented by sonication. The tagged locus is then immunoprecipitated and the crosslinking is reversed. Finally, the proteins or RNAs that are associated with the isolated chromatin are subjected to mass spectrometric or RNA sequencing analyses, respectively. This approach allows the successful identification of proteins and RNAs associated with a genomic region of interest.

\section{Video Link}

The video component of this article can be found at https://www.jove.com/video/53478/

\section{Introduction}

The identification of molecules associated with specific genomic regions of interest is required to understand the mechanisms of regulation of genomic functions such as transcription and epigenetic regulation. Although several techniques have been developed for biochemical analysis of specific genomic regions ${ }^{1-7}$, they are not used widely at this stage because of their intrinsic problems such as limited application (e.g., only for high-copy number loci or loci with repeats) and too much time and efforts required.

In order to perform biochemical analysis of specific genomic regions easily, we have developed two locus-specific chromatin immunoprecipitation (ChIP) technologies, namely insertional ChIP (iChIP) ${ }^{8-13}$ and engineered DNA-binding molecule-mediated ChIP (enChIP) $)^{14-17}$. In iChIP, a locus of interest is tagged by inserting recognition sequences of an exogenous DNA-binding protein such as LexA. The locus is then isolated by affinity purification using the tagged DNA-binding protein. In enChIP, engineered DNA-binding molecules, such as zinc-finger proteins, transcription activator-like (TAL) proteins, and clustered regularly interspaced short palindromic repeats (CRISPR) complexes, are used to tag a locus of interest (Figure 1). Subsequently, the genomic region is isolated by affinity purification of the tagged DNA-binding molecules.

One of the advantages of enChIP over iChIP is that insertion of recognition sequences of an exogenous DNA-binding protein is not necessary. Targeting of loci using CRISPR complexes consisting of a catalytically inactive form of Cas9 (dCas9) and a guide RNA (gRNA) is much easier than targeting of these regions by iChIP or enChIP using TAL and zinc-finger proteins. Here, we describe a step-by-step protocol for enChIP combined with mass spectrometry and RNA sequencing (RNA-Seq) to identify locus-associated proteins and RNAs, respectively.

\section{Design of Engineered DNA-binding Molecules Recognizing the Target Locus}

1. For enChIP using CRISPR complexes, use the CRISPRdirect web tool (http://crispr.dbcls.jp) to identify candidate gRNA target sequences in the genomic region of interest described as previously ${ }^{18}$. This web tool returns 23 bp genomic sites of the form $5^{\prime}-\mathrm{N}_{20} \mathrm{NGG} \mathrm{3}^{\prime}$ within the target region.

2. Synthesize a gBlock including the U6 promoter sequence and the sequence of $5^{\prime}-\mathrm{N}_{20}$ in $5^{\prime}-\mathrm{N}_{20} \mathrm{NGG-3}$ ' using commercial services (see Figure 2) ${ }^{19,20}$. For subcloning purposes, include appropriate restriction enzyme sites outside of the gBlock.

3. Insert the gBlock into an appropriate vector as previously described ${ }^{16}$. Several retroviral vectors for gBlocks are available (see Materials). 
4. For enChIP using TAL proteins, design TAL proteins recognizing the target loci. Generate plasmids encoding TAL proteins using commercial services. Generate expression vectors containing the TAL proteins fused with one or more tags such as $3 \times$ FLAG as previously described ${ }^{15}$.

\section{Establishment of Cells for the enChIP Analysis}

1. Express $3 \times$ FLAG-dCas 9 and the gRNA (CRISPR-based procedure) or 3×FLAG-TAL (TAL protein-based procedure) in the cells to be analyzed as described previously ${ }^{94-17}$.

1. Use transient transfection if the transfection efficiency is high. An expression vector containing $3 \times F L A G-d C a s 9$ and the CMV promoter is available (see Materials).

2. Consider establishing stable transformants using conventional methods if the transient transfection efficiency is low. In addition to the aforementioned retroviral vectors for gBlock, retroviral vectors of 3×FLAG-dCas9 are available (see Materials).

2. Confirm the expression of the 3xFLAG-dCas9 or 3xFLAG-TAL protein in the transfected cells by immunoblot analysis using an anti-FLAG antibody $(\mathrm{Ab})$ as described previously ${ }^{14-17}$.

Note: Expression of these tagged proteins can also be confirmed by intracellular staining with anti-FLAG-FITC and a subsequent FACS analysis. A protocol for intracellular staining can be downloaded from our homepage (http://www.biken.osaka-u.ac.jp/lab/microimm/fujii/ iChIP_protocols/english.html).

3. Confirm expression of the gRNA by standard RT-PCR technique.

4. For quantitative identification of proteins interacting with the genomic region of interest, consider use of a stable isotope labeling by amino acids in cell culture (SILAC) analysis combined with enChIP (enChIP-SILAC).

Note: Media for the SILAC analysis can be purchased from commercial vendors. SILAC is powerful in detecting specific interactions.

1. Culture cells in SILAC heavy medium. Prepare cells cultured in SILAC light medium as a negative control. Use at least $5 \times 10^{7}$ cells for each SILAC medium (heavy or light). For efficient labeling, add both L-Lysine-2 $\mathrm{HCl},{ }^{13} \mathrm{C}_{6}$ and L-Arginine-HCl, ${ }^{13} \mathrm{C}_{6},{ }^{15} \mathrm{~N}_{4}$ in the SILAC Heavy media. Note: At least five cell divisions are necessary to label proteins.

1. For example, culture human fibrosarcoma HT1080 cells stably expressing $3 x F L A G-d C a s 9$ and a gRNA at $37{ }^{\circ} \mathrm{C}$ and $5 \% \mathrm{CO}_{2}$ in DMEM media for SILAC and dialyzed fetal bovine serum with Lysine-2 $\mathrm{HCl}$ plus L-Arginine-HCl (Light medium) or ${ }^{13} \mathrm{C}_{6} \mathrm{~L}-$ Lysine-2 $\mathrm{HCl}$ plus ${ }^{13} \mathrm{C}_{6}{ }^{15} \mathrm{~N}_{4} \mathrm{~L}$-Arginine-HCl (Heavy medium) (see Materials) ${ }^{16}$. Add $50 \mathrm{mg}$ of light or heavy L-Lysine-2 $\mathrm{HCl}$ and LArginine- $\mathrm{HCl}$ in $500 \mathrm{ml}$ of medium.

2. Trypsinize and replate cells before they become confluent so that cells maintain exponential growth.

\section{Crosslinking of Cells with Formaldehyde}

1. For cells in suspension culture, transfer $2 \times 10^{7}$ cells expressing 3xFLAG-TAL proteins or 3xFLAG-dCas 9 plus gRNA and suspend in 30 ml of regular culture medium in a $50 \mathrm{ml}$ centrifuge tube. When more cells are used, increase the volumes and amounts of reagents proportionally. For SILAC experiments, mix the cells cultured in heavy medium or light medium $\left(5 \times 10^{7}\right.$ cells each) and divide the total of $1 \times 10^{8}$ cells into 5 tubes containing $2 \times 10^{7}$ cells.

2. Add $810 \mu \mathrm{l}$ of $37 \%$ formaldehyde to $30 \mathrm{ml}$ of the cell suspension (final concentration $1 \%$ ) and incubate at $37^{\circ} \mathrm{C}$ for $5 \mathrm{~min}$. For adherent cells, directly fix cells in culture dishes by adding $810 \mu \mathrm{l}$ of $37 \%$ formaldehyde to $30 \mathrm{ml}$ of culture medium.

3. Stop the crosslinking by adding $3.1 \mathrm{ml}$ of $1.25 \mathrm{M}$ glycine solution (final concentration $127 \mathrm{mM}$ ), and incubate at RT for $10 \mathrm{~min}$.

4. Collect cells by centrifugation $\left(300 \times \mathrm{g}\right.$ for $5 \mathrm{~min}$ at $\left.4{ }^{\circ} \mathrm{C}\right)$. Carefully discard the supernatant including formaldehyde and store it in an appropriate waste bottle.

1. For adherent cells, detach cells with a cell scraper and harvest in a $50 \mathrm{ml}$ tube, and collect cells as described in this step.

2. For SILAC experiments, mix the detached cells cultured in heavy medium or light medium $\left(5 \times 10^{7}\right.$ cell each), divide the total of $1 \times 10^{8}$ cells into 5 tubes containing $2 \times 10^{7}$ cells, and collect cells as described in this step.

5. Wash the cell pellet with $30 \mathrm{ml}$ of PBS twice per tube. Carefully discard the supernatant including formaldehyde and store it in an appropriate waste bottle. Handle the formaldehyde waste according to chemical safety guidelines. The fixed cells can be frozen and stored at $-80{ }^{\circ} \mathrm{C}$.

\section{Preparation of Chromatin (per $2 \times 10^{7}$ cells)}

1. Suspend the fixed cells in $10 \mathrm{ml}$ of cell lysis buffer (10 mM Tris ( $\mathrm{pH} 8.0), 1 \mathrm{mM}$ EDTA, $0.5 \%$ IGEPAL CA-630, and $1 \times$ protease inhibitors) and incubate on ice for $10 \mathrm{~min}$.

2. Centrifuge the sample $\left(830 \times \mathrm{g}\right.$ at $4{ }^{\circ} \mathrm{C}$ for $\left.8 \mathrm{~min}\right)$ and discard the supernatant carefully.

3. Suspend the pellet in $10 \mathrm{ml}$ of nuclear lysis buffer (10 mM Tris ( $\mathrm{pH} 8.0$ ), $1 \mathrm{mM}$ EDTA, $0.5 \mathrm{M} \mathrm{NaCl}, 1 \%$ Triton X-100, $0.5 \%$ sodium deoxycholate, $0.5 \%$ lauroylsarcosine, and $1 \mathrm{x}$ protease inhibitors). Incubate on ice for $10 \mathrm{~min}$ and vortex every 2-3 min.

4. Centrifuge the sample $\left(830 \times \mathrm{g}\right.$ at $4{ }^{\circ} \mathrm{C}$ for $\left.8 \mathrm{~min}\right)$ and discard the supernatant carefully.

5. Wash the pellet in $10 \mathrm{ml}$ of PBS. The pellet (chromatin fraction) can be stored at $-80^{\circ} \mathrm{C}$ after immediate freezing in liquid nitrogen.

\section{Sonication of Chromatin (per $2 \times 10^{7}$ cells)}

1. Suspend the chromatin fraction in $800 \mu \mathrm{l}$ of modified lysis buffer 3 (10 mM Tris (pH 8.0), $1 \mathrm{mM}$ EDTA, $150 \mathrm{mM} \mathrm{NaCl}, 0.1 \%$ sodium deoxycholate, $0.1 \%$ SDS, and $1 \times$ protease inhibitors) and transfer into a $1.5 \mathrm{ml}$ tube.

2. Sonicate the chromatin using a sonicator (see Materials) and the following conditions: output: 3 ; duty: $100 \%$ (continuous); and time: free. Perform 10-18 cycles of sonication for $10 \mathrm{sec}$ and cooling on ice for $20 \mathrm{sec}$. To avoid excessive heating, incubate the samples on ice for 2 min every 5-6 cycles. To avoid foaming, keep the position of the tip of the sonication probe $0.5 \mathrm{~cm}$ above the bottom of the tube. 
3. Centrifuge the sample at $\left(16,000 \times \mathrm{g}\right.$ at $4{ }^{\circ} \mathrm{C}$ for $\left.10 \mathrm{~min}\right)$ and transfer the supernatant into a $1.5 \mathrm{ml}$ tube. The sonicated chromatin can be stored at $-80^{\circ} \mathrm{C}$ after immediate freezing in liquid nitrogen.

\section{Evaluation of Chromatin Fragmentation}

1. Mix $10 \mu \mathrm{l}$ of the fragmented chromatin with $85 \mu \mathrm{l}$ of distilled water.

2. Add $4 \mu \mathrm{l}$ of $5 \mathrm{M} \mathrm{NaCl}$ and incubate at $65^{\circ} \mathrm{C} \mathrm{O} / \mathrm{N}$.

3. Add $1 \mu \mathrm{l}$ of $10 \mathrm{mg} / \mathrm{ml} \mathrm{RNase} A$ and incubate at $37^{\circ} \mathrm{C}$ for $45 \mathrm{~min}$.

4. Add $2 \mu \mathrm{l}$ of $0.5 \mathrm{M}$ EDTA ( $\mathrm{pH} 8.0$ ), $4 \mu \mathrm{l}$ of $1 \mathrm{M}$ Tris $(\mathrm{pH} 6.8)$, and $1 \mu \mathrm{l}$ of $20 \mathrm{mg} / \mathrm{ml}$ Proteinase $\mathrm{K}$, and then incubate at $45^{\circ} \mathrm{C}$ for $1.5 \mathrm{hr}$.

5. Separate $10 \mu \mathrm{l}$ of the sample by electrophoresis in a $1 \%$ agarose gel that does not contain staining dyes such as SYBR Green.

6. Stain the gel to evaluate the distribution of the lengths of the fragmented chromatin. Conditions that generate an average length of $0.5-2 \mathrm{kbp}$ (range of $0.2-4 \mathrm{kbp}$ ) are recommended.

7. Purify DNA from the remaining samples by phenol-chloroform extraction or by using a DNA extraction kit (see Materials). The purified DNA can be used as input DNA to estimate the yields of enChIP analyses (see 8.11).

\section{Preparation of Dynabeads Conjugated with Antibodies (per $2 \times 10^{7}$ cells)}

1. Prepare two $1.5 \mathrm{ml}$ tubes, one for pre-clearing using normal mouse IgG and the other for incubation with the anti-FLAG Ab. Add $150 \mu \mathrm{l}$ of Protein G-conjugated magnetic beads (see Materials) to each tube.

2. Place the tubes on a magnet stand and wait for $3 \mathrm{~min}$. Discard the supernatant by pipetting.

3. Suspend the beads in $1 \mathrm{ml}$ of PBS containing $0.01 \%$ Tween-20 (PBS-T). Place the tubes on a magnetic stand and wait for 2 min. Discard the supernatant by pipetting, and then repeat the step.

4. Suspend the beads in $1 \mathrm{ml}$ of PBS-T containing $0.1 \% \mathrm{BSA}$.

5. Add $15 \mu \mathrm{g}$ of normal mouse IgG or anti-FLAG Ab and rotate at $4{ }^{\circ} \mathrm{C} \mathrm{O} / \mathrm{N}$

6. Spin down briefly, then place the tubes on a magnet stand and wait for $3 \mathrm{~min}$. Discard the supernatant by pipetting.

7. Suspend the beads in $1 \mathrm{ml}$ of PBS-T. Invert the sample several times and spin down briefly. Place the tubes on a magnet stand and wait for 3 min, then discard the supernatant by pipetting. Repeat the wash two more times with PBS-T (total of three wash steps).

\section{Chromatin Immunoprecipitation (per $2 \times 10^{7}$ cells)}

1. Mix the fragmented chromatin prepared in 5.3) (approximately $800 \mu \mathrm{l}$ ) with one-fifth of the volume (approximately $200 \mu \mathrm{l}$ ) of modified lysis buffer 3 containing $5 \%$ Triton X-100 (final concentration of $1 \%$ Triton X-100).

2. Add the chromatin solution to the tube in which Protein G-conjugated magnetic beads conjugated with normal mouse IgG were prepared. Rotate at $4{ }^{\circ} \mathrm{C}$ for $1 \mathrm{hr}$.

3. Place the tube on a magnet stand and wait for 3 min.

4. Transfer the supernatant into the tube in which Protein G-conjugated magnetic beads conjugated with anti-FLAG Ab were prepared. Rotate at $4{ }^{\circ} \mathrm{C} \mathrm{O} / \mathrm{N}$.

5. Place the tube on a magnet stand and wait for $3 \mathrm{~min}$. Discard the supernatant by pipetting.

6. Suspend the beads in $1 \mathrm{ml}$ of low salt buffer ( $20 \mathrm{mM}$ Tris ( $\mathrm{pH} 8.0), 2 \mathrm{mM}$ EDTA, $150 \mathrm{mM} \mathrm{NaCl}, 1 \%$ Triton X-100, 0.1\% SDS, and $1 \times$ protease inhibitors) and rotate at $4{ }^{\circ} \mathrm{C}$ for $5 \mathrm{~min}$. Place the tube on a magnet stand and wait for $3 \mathrm{~min}$. Discard the supernatant by pipetting and repeat the wash step.

7. Wash the beads with high salt buffer ( $20 \mathrm{mM}$ Tris (pH 8.0), $2 \mathrm{mM}$ EDTA, $500 \mathrm{mM} \mathrm{NaCl}, 1 \%$ Triton X-100, $0.1 \%$ SDS, and 1x protease inhibitors) twice.

8. Wash the beads with $\mathrm{LiCl}$ buffer (10 mM Tris (pH 8.0), 1 mM EDTA, $250 \mathrm{mM} \mathrm{LiCl,} \mathrm{0.5 \%} \mathrm{IGEPAL} \mathrm{CA-630,} \mathrm{0.5 \%} \mathrm{sodium} \mathrm{deoxycholate,} \mathrm{and} \mathrm{1x}$ protease inhibitors) twice.

9. Wash the beads with TBS-IGEPAL CA-630 (50 mM Tris ( $\mathrm{pH} 7.5), 150 \mathrm{mM} \mathrm{NaCl}, 0.1 \%$ IGEPAL CA-630, and 1x protease inhibitors) once.

10. Suspend the beads in $200 \mu$ l of elution buffer $(50 \mathrm{mM}$ Tris $(\mathrm{pH} 7.5), 150 \mathrm{mM} \mathrm{NaCl}, 0.1 \%$ IGEPAL CA-630, $1 \times$ protease inhibitors, and $500 \mu \mathrm{g} /$ $\mathrm{ml} 3 \times$ FLAG peptide) and incubate at $37^{\circ} \mathrm{C}$ for $20 \mathrm{~min}$. Place the tube on a magnet stand and wait for 3 min. Transfer the supernatant into a new $1.5 \mathrm{ml}$ tube and repeat the elution step.

11. Purify DNA from small portion (e.g., $5 \%$ ) of the eluate by phenol-chloroform extraction or by using a DNA extraction kit (see Materials). The purified DNA can be used for PCR with specific primer sets to estimate the yields of enChIP analyses by comparing with input DNA prepared in Step 6.7 as described previously ${ }^{14,16}$.

\section{SDS-PAGE, Staining, and Mass Spectrometric Analysis}

1. Mix the eluate $(400 \mu \mathrm{l})$ with $1 \mathrm{ml}$ of 2 -propanol, $50 \mu \mathrm{l}$ of $3 \mathrm{M}$ sodium acetate $(\mathrm{pH} 5.2)$, and $5 \mu \mathrm{l}$ of $20 \mathrm{mg} / \mathrm{ml}$ glycogen. Precipitate the chromatin at $-20^{\circ} \mathrm{C} \mathrm{O} / \mathrm{N}$.

2. Centrifuge the sample $\left(16,000 \times \mathrm{g}\right.$ at $4{ }^{\circ} \mathrm{C}$ for $\left.30 \mathrm{~min}\right)$ and discard the supernatant. Rinse the pellet with $1 \mathrm{ml}$ of $70 \%$ ethanol and centrifuge again $\left(16,000 \times \mathrm{g}\right.$ at $4{ }^{\circ} \mathrm{C}$ for $\left.10 \mathrm{~min}\right)$. Discard the supernatant completely by pipetting.

3. Suspend the pellet in $40 \mu \mathrm{l}$ of $2 x$ sample buffer (125 mM Tris (pH 6.8), 10\% 2-mercaptoethanol, $4 \%$ SDS, $10 \%$ sucrose, and $0.004 \%$ bromophenol blue). Vortex for $5 \mathrm{~min}$ to dissolve the pellet completely, and then incubate at $100^{\circ} \mathrm{C}$ for 30 min to denature the proteins and reverse the crosslinking.

4. For SDS-PAGE, run $40 \mu \mathrm{l}$ of the sample on the gel until the dye reaches $1 \mathrm{~cm}$ below the well. Note: We usually use $4-20 \%$ gradient gels, but other \% gels can be used.

5. Stain the gel with Coomassie Brilliant Blue or silver stain

6. Cut the gel into five pieces (2 $\mathrm{mm}$ height).

7. Perform in gel digestion and mass spectrometric analysis as described previously ${ }^{13-16}$. 
8. For SILAC experiments with $5 \times 10^{7}$ cells each (total of $1 \times 10^{8}$ cells), suspend pellet from the initial five tubes in $40 \mu$ l of $2 \times$ sample buffer (it is not necessary to scale up).

\section{Purification of RNA and RNA-Seq Analysis}

1. To purify the RNA after enChIP, add $5 \mathrm{U} / \mathrm{ml}$ of RNase Inhibitor (see Materials) to all of the buffer solutions, except modified lysis buffer 3 and the elution buffer, to which add $40 \mathrm{U} / \mathrm{ml}$ of RNase Inhibitor.

2. Mix the eluate $(400 \mu \mathrm{l})$ with $16 \mu \mathrm{l}$ of $5 \mathrm{M} \mathrm{NaCl}$ and incubate at $65^{\circ} \mathrm{C}$ for $2 \mathrm{hr}$.

3. Add $1 \mathrm{ml}$ of acid-guanidinium-phenol-based reagent (see Materials) to the sample. Vortex for $15 \mathrm{sec}$ and then incubate at RT for 5-15 min. Centrifuge the sample for $15 \mathrm{~min}$ at $12,000 \times \mathrm{g}$ and RT.

4. Transfer the supernatant to a new $1.5 \mathrm{ml}$ tube and add $5 \mu \mathrm{l}$ of p-bromoanisole. Vortex for $15 \mathrm{sec}$ and then incubate at RT for 3-5 min. Centrifuge the sample for $10 \mathrm{~min}$ at $12,000 \times \mathrm{g}$ and $\mathrm{RT}$.

5. Transfer the supernatant (approximately $1 \mathrm{ml}$ ) into a new $2 \mathrm{ml}$ tube and add $1 \mathrm{ml}$ of 2-propanol. Invert the tube and incubate at RT for $10 \mathrm{~min}$. Load the mixture onto a column in an RNA purification kit (see Materials). Centrifuge the column for $1 \mathrm{~min}$ at $12,000 \times \mathrm{g}$ and RT.

6. Wash the column with $400 \mu$ l of RNA Wash Buffer in an RNA purification kit (see Materials).

7. Add $80 \mu \mathrm{l}$ of DNase I cocktail (mixture of $5 \mu \mathrm{l}$ of DNase I ( $1 \mathrm{U} / \mu \mathrm{l}), 8 \mu \mathrm{l}$ of $10 \times$ DNase I Reaction Buffer, $3 \mu \mathrm{l}$ of DNase/RNase-free water, and $64 \mu \mathrm{l}$ of RNA Wash Buffer in an RNA purification kit (see Materials)) to the column. Incubate the sample at $37^{\circ} \mathrm{C}$ for 15 min and then centrifuge for $30 \mathrm{sec}$ at $12,000 \times \mathrm{g}$ and RT.

8. Wash the column with $400 \mu$ l of RNA PreWash Buffer in an RNA purification kit (see Materials) twice.

9. Elute the RNA with $50 \mu$ l of DNase/RNase-free water. The eluted RNA can be used for RNA sequencing.

\section{Representative Results}

Overall, $1-30 \%$ of target genomic regions can be purified using enChIP. Figure 3 includes representative data showing the yields of enChIP analyses targeting telomeres and the promoter of the interferon (IFN) regulatory factor-1 (IRF-1) gene. As examples of typical results, Table 1 lists the proteins associated with the IRF-1 promoter in an IFNY-specific manner identified by enChIP-SILAC, Table 2 lists the telomere-binding proteins identified by enChIP combined with mass spectrometry (enChIP-MS), and Table 3 lists the RNAs associated with telomeres identified by enChIP-RNA-Seq. 

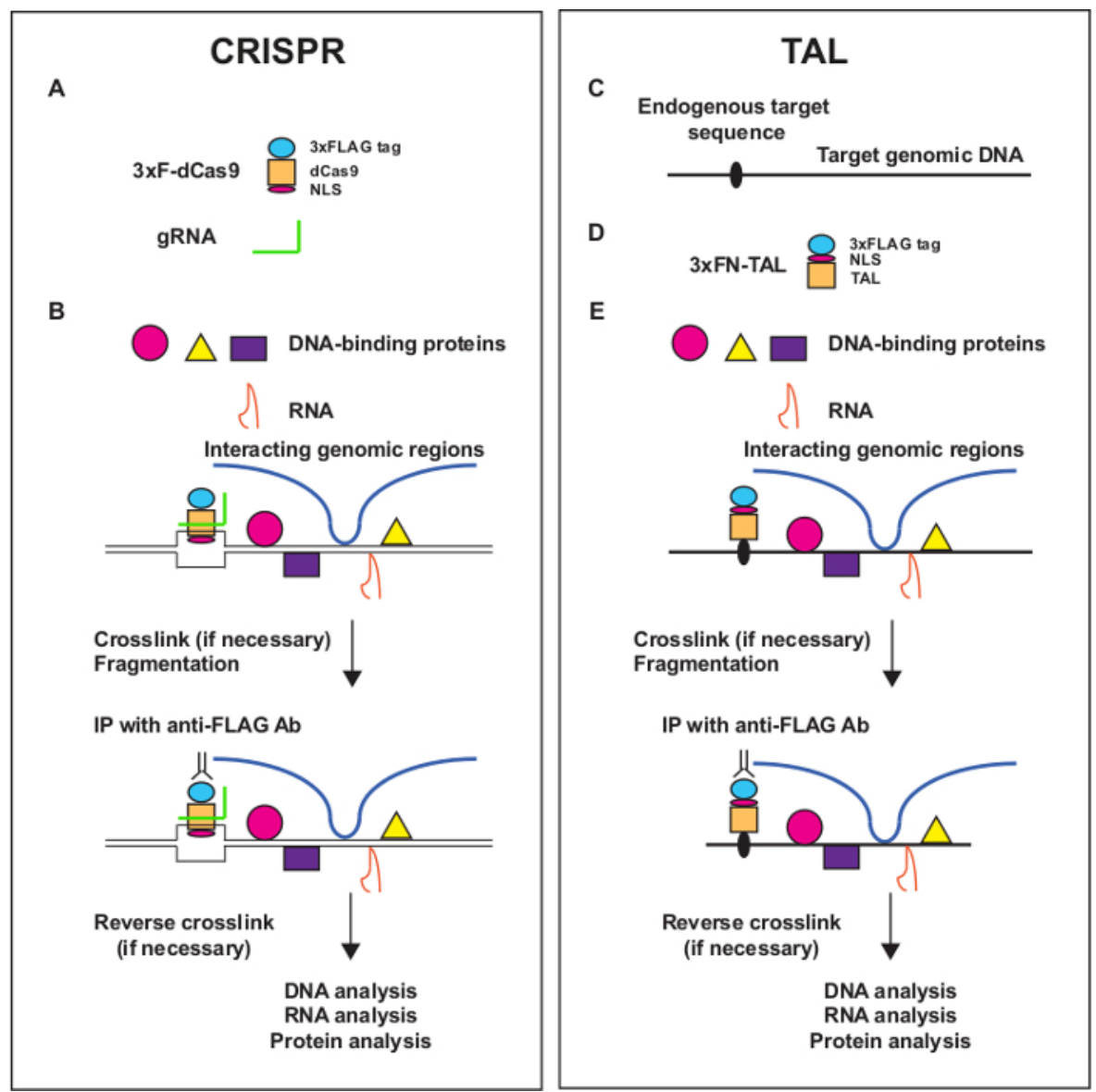

Figure 1. Overview of enChIP. enChIP using CRISPR $(A, B)$ and TAL $(C, D, E)$ is shown. A locus of interest is tagged with engineered DNAbinding molecules such as a TAL protein or the CRISPR system consisting of a catalytically inactive form of Cas9 (dCas) and guide RNA (gRNA). The molecular interactions are fixed with formaldehyde or other crosslinkers, if necessary. Subsequently, fixed chromatin is fragmented by sonication or enzymatic digestion. The tagged genomic regions are purified by affinity purification. Finally, crosslinking is reversed, and interacting molecules (genomic regions, RNAs, and proteins) are identified using next generation sequencing and mass spectrometry. Please click here to view a larger version of this figure.

TGTACAAAAAAGCAGGCTTTAAAGGAACCAATTCAGTCGACTGGATCCGGTACCAAGGT
CGGGCAGGAAGAGGGCCTATTTCCCATGATTCCTTCATATTTGCATATACGATACAAGG

CTGTTAGAGAGATAATTAGAATTAATTTGACTGTAAACACAAAGATATTAGTACAAAAT

ACGTGACGTAGAAAGTAATAATTTCTTGGGTAGTTTGCAGTTTTAAAATTATGTTTTAA

AATGGACTATCATATGCTTACCGTAACTTGAAAGTATTTCGATTTCTTGGCTTTATATA

TCTTGTGGAAAGGACGAAACACCGNNNNNNNNNNNNNNNNNNNNGTTTTAGAGCTAGAA

\section{ATAGCAAGTTAAAATAAGGCTAGTCCGTTATCAACTTGAAAAAGTGGCACCGAGTCGGT}

GCTTTTTTTT

Figure 2. Sequence of gBlock. The U6 promoter (in black), the G nucleotide before the guide sequence (in blue), the guide sequence (gRNA spacer) (in red), the scaffold sequence (in green), and the terminator sequence (in orange) are shown. 
A

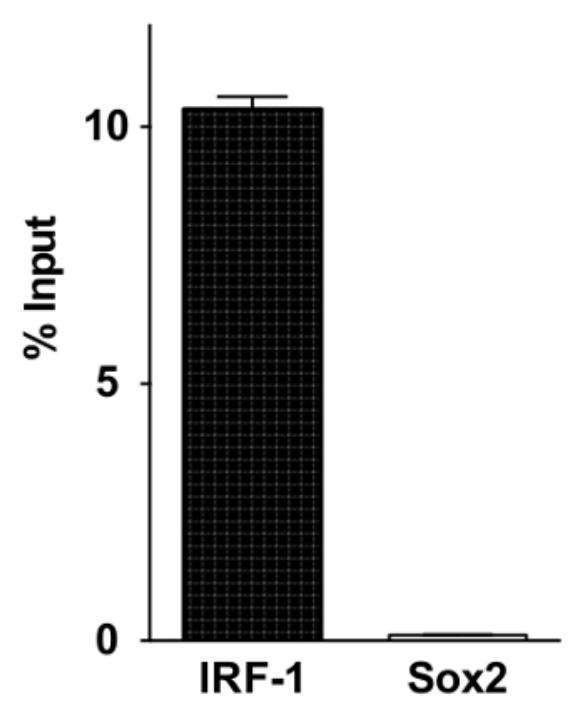

B

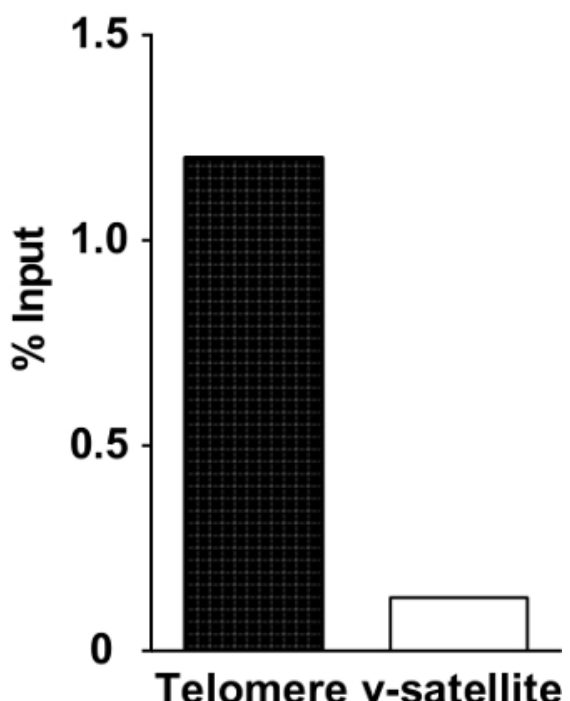

Figure 3. Yields of representative enChIP analyses. (A) Percentage inputs for the target IRF-1 locus and the non-target Sox2 locus. (B) Percentage inputs for the target telomeres and non-target $y$-satellites. The figures have been adapted and modified from previous publications $^{15,16}$

\begin{tabular}{|l|l|}
\hline Categories & Proteins \\
\hline Transcription & $\begin{array}{l}\text { DDX1, PARP1, CKAP4, Pescadillo homolog, PUR } \beta, \\
\text { activated RNA polymerase II transcriptional activator p15, } \\
\text { BTF3, Myb-binding protein 1A }\end{array}$ \\
\hline $\begin{array}{l}\text { Histone deacetylation, } \\
\text { corepressor components }\end{array}$ & RBBP4, PA2G4, TBL3 \\
\hline Acetyltransferase & Protein arginine N-methyltransferase 1 \\
\hline DNA topoisomerase & DNA topoisomerase 2a \\
\hline Histones & Histone H2A.Z, histone H3.2 \\
\hline
\end{tabular}

Table 1: Examples of proteins associated with the human IRF-1 promoter region in an IFNy-specific manner identified by enChIP.

SILAC. The table has been adapted from a previous publication ${ }^{16}$.

\begin{tabular}{|l|l|}
\hline Categories & Proteins \\
\hline Mammalian telomere-binding proteins & PML, RPA, CDK1, PARP1, PCBP1 \\
\hline $\begin{array}{l}\text { Telomere-binding proteins in yeast } \\
\text { or other organisms }\end{array}$ & IMP4 \\
\hline $\begin{array}{l}\text { Proteins interacting with telomere-binding } \\
\text { proteins [associated telomere-binding protein] }\end{array}$ & $\begin{array}{l}\text { DNA polymerase } \alpha \text { (POLA1) [Cdc13p], } \\
\text { ARMC6 [TRF2], CTBP1 [FoxP2-POT1], } \\
\text { exportin-5 [TERT], GNL3L [TRF1], } \\
\text { exportin-1 [TERT], 14-3-3 [TERT] }\end{array}$ \\
\hline Proteins localizing to heterochromatin & BEND3 \\
\hline Proteins regulating epigenetic marks & KDM5C \\
\hline Proteins whose mutations affect telomere function & $\begin{array}{l}\text { DNA polymerase } \alpha \text { (POLA1), HAT1, Nup133, } \\
\text { CDK7, DPOE1, PRDX1, TYSY, } \\
\text { glutamate-cysteine ligase, glutaredoxin, SMRC1 }\end{array}$ \\
\hline
\end{tabular}

Table 2: Examples of proteins associated with mouse telomeres identified by enChIP-MS. The table has been adapted from a previous publication $^{15}$. 


\begin{tabular}{|l|l|}
\hline Categories & RNAs \\
\hline Telomerase components & Terc, Rmrp \\
\hline Telomeric RNAs & TERRAs \\
\hline scaRNAs & Scarna6, Scarna10, Scarna13, Scarna2 \\
\hline H/ACA snoRNAs & Snora23, Snora74a, Snora73b, Snora73a \\
\hline C/D snoRNAs & Snord17, Snord15a, Snord118 \\
\hline IncRNA & Neat1 \\
\hline
\end{tabular}

Table 3: Examples of RNAs associated with mouse telomeres identified by enChIP-RNA-Seq. The table has been adapted from a previous publication $^{17}$.

\section{Discussion}

Here, we describe the purification of specific genomic regions using engineered DNA-binding molecules such as the CRISPR system and TAL proteins, and the identification of proteins and RNAs bound to these genomic regions. Binding of engineered DNA-binding molecules to the genome may affect chromatin structure, including nucleosome positioning, and may abrogate genomic functions, as described in CRISPR interference experiments ${ }^{21}$. To avoid these potential aberrant effects, we propose specific guidelines for choosing target genomic regions. First, to avoid potential inhibition of the recruitment of RNA polymerases and transcription factors, as well as disruption of nucleosome positioning around the transcription start site, the target regions for analyses of promoter regions should be several hundred base pairs upstream of (5' to) the transcription start site. By contrast, when analyzing genomic regions with distinct boundaries, such as enhancers and silencers, genomic regions that are directly juxtaposed to these regions can be targeted because it is less likely that the binding of engineered DNA-binding molecules will affect their functions. Furthermore, it is best to avoid using target regions that are conserved among different species, because important DNA-binding molecules often bind to evolutionarily conserved regions and inhibition of their binding might disrupt the functions of the target genomic regions. In this regard, it is always necessary to check that the function of the target genomic region is maintained in the established cells used for enChIP analyses. Because multiple gRNAs can be tested easily and it is tedious and expensive to generate multiple versions of TAL or zinc-finger proteins recognizing different target genomic regions, enChIP using CRISPR is more advantageous than enChIP using other proteins.

It has been shown that dCas9 binds to off-target sites although affinity to those sites might be weaker than that to the target sites ${ }^{22-25}$. There are several ways to manage contamination of molecules bound to those off-target sites. First, the use of several, at least two, different gRNAs would be recommended. Those molecules commonly observed in enChIP using distinct gRNAs would be true positives. Second, comparison of different conditions for enChIP would be effective in cancelling contamination of non-specific molecules and molecules bound to off-target sites. Examples of those comparison sets would be (i) stimulation (-) and (+), or (ii) different cell types such as T cells vs. B cells. Finally, quantitative analysis of binding of candidate molecules should be performed to confirm their specific binding to the target sites. It is preferable to prepare cells expressing only dCas9 but not gRNA as a negative control.

Using enChIP analyses, we were able to successfully identify a number of known and novel molecules interacting with specific genomic regions (Tables 1-3) ${ }^{14-17}$. However, this technique failed to detect some other known proteins interacting with these regions. For example, STAT1 reportedly associates with the IRF-1 promoter upon IFNY stimulation ${ }^{8}$, but our enChIP-SILAC analysis did not detect STAT1 as a protein induced to interact with this genomic region ${ }^{16}$. In addition, in the enChIP-MS analysis of telomeres, we did not detect shelterin proteins consisting of TRF-1 and TRF- $2^{15}$, which have been shown to interact with telomeres ${ }^{26}$. There are a few potential reasons for these discrepancies. First, the stoichiometry of binding of Stat1 to the IRF-1 promoter might be very low. It is reasonable that enChIP-MS, including enChIP-SILAC, detects proteins that are more abundantly associated with target genomic regions; hence, the analysis of more cells might be necessary to detect these proteins. Increases in the sensitivities of MS instruments would also contribute to the efficient detection of proteins with low stoichiometric binding. Second, some proteins, possibly including Stat1 and shelterins, might be difficult targets for MS analyses. Third, in our analysis of telomere-binding proteins ${ }^{15}$, the $3 \times$ FLAG-TAL proteins recognizing telomeres ( $\left.3 \times F N-T e l-T A L\right)$ might have blocked the binding of shelterins to telomeres in a competitive fashion.

In contrast to the relative difficulty of detecting transcription factors binding to specific genomic regions using enChIP, we successfully identified epigenetic regulators such as histone modification enzymes using enChIP analyses. The success of this technique may be due to the fact that epigenetic regulators bind to a broad range of genomic regions; hence, more proteins per genomic region are available for MS. Because epigenetic regulators are increasingly recognized as important targets for drugs against intractable diseases such as cancer, enChIP would be a useful tool for the identification of epigenetic drug targets.

\section{Disclosures}

The authors have filed a patent on enChIP (Patent name: 'Method for isolating specific genomic regions using DNA-binding molecules recognizing endogenous DNA sequences'; Patent number: PCT/JP2013/74107). H.F. is a member of the Advisory Board of Addgene.

\section{Acknowledgements}

This work was supported by Takeda Science Foundation (T.F.); the Asahi Glass Foundation; the Uehara Memorial Foundation (H.F.); the Kurata Memorial Hitachi Science and Technology Foundation (T.F. and H.F.); Grant-in-Aid for Young Scientists (B) (\#25830131), Grant-in-Aid for Scientific Research (C) (\#15K06895) (T.F.); and a Grant-in-Aid for Scientific Research on Innovative Areas 'Transcription Cycle' (\#25118512 
\& \#15H01354), Grant-in-Aid for Scientific Research (B) (\#15H04329), Grant-in-Aid for Exploratory Research (\#26650059) and 'Genome Support' (\#221S0002) (H.F.) from the Ministry of Education, Culture, Sports, Science and Technology of Japan.

\section{References}

1. Zhang, X. Y., \& Horz, W. Analysis of highly purified satellite DNA containing chromatin from the mouse. Nucleic Acids Res. 10, 1481-1494 (1982).

2. Workman, J. L., \& Langmore, J. P. Nucleoprotein hybridization: a method for isolating specific genes as high molecular weight chromatin Biochemstry. 24, 7486-7497 (1985).

3. Boffa, L. C., Carpaneto, E. M., \& Allfrey, V. G. Isolation of active genes containing CAG repeats by DNA strand invasion by a peptide nucleic acid. Proc. Natl. Acad. Sci. USA. 92, 1901-1905 (1995).

4. Jaskinskas, A., \& Hamkalo, B. A. Purification and initial characterization of primate satellite chromatin. Chromosome Res. 7, 341-354 (1999).

5. Griesenbeck, J., Boeger, H., Strattan, J. S., \& Kornberg, R. D. Affinity purification of specific chromatin segments from chromosomal loci in yeast. Mol. Cell Biol. 23, 9275-9282 (2003).

6. Ghirlando, R., \& Felsenfeld, G. Hydrodynamic studies on defined heterochromatin fragments support a $30-\mu m$ fiber having six nucleosomes per turn. J. Mol. Biol. 376, 1417-1425 (2008).

7. Déjardin, J., \& Kingston, R. E. Purification of proteins associated with specific genomic loci. Cell. 136, 175-186 (2009).

8. Hoshino, A., \& Fujii, H. Insertional chromatin immunoprecipitation: a method for isolating specific genomic regions. J. Biosci. Bioeng. 108, 446-449 (2009).

9. Fujita, T., \& Fujii, H. Direct idenification of insulator components by insertional chromatin immunoprecipitation. PLoS One. 6, e26109 (2011).

10. Fujita, T., \& Fujii, H. Efficient isolation of specific genomic regions by insertional chromatin immunoprecipitation (iChIP) with a secondgeneration tagged LexA DNA-binding domain. Adv. Biosci. Biotechnol. 3, 626-629 (2012).

11. Fujita, T., \& Fujii, H. Locus-specific biochemical epigenetics / chromatin biochemistry by insertional chromatin immunoprecipitation. ISRN Biochem. 2013, Article ID 913273 (2013).

12. Fujita, T., \& Fujii, H. Efficient isolation of specific genomic regions retaining molecular interactions by the iChIP system using recombinant exogenous DNA-binding proteins. BMC Mol. Biol. 15, 26 (2014).

13. Fujita, T., Kitaura, F., \& Fujii, H. A critical role of the Thy28-MYH9 axis in B cell-specific expression of the Pax5 gene in chicken B cells. PLoS One. 10, e0116579 (2015).

14. Fujita, T., \& Fujii, H. Efficient isolation of specific genomic regions and identification of associated proteins by engineered DNA-binding molecule-mediated chromatin immunoprecipitation (enChIP) using CRISPR. Biochem. Biophys. Res. Commun. 439, 132-136 (2013).

15. Fujita, T. et al. Identification of telomere-associated molecules by engineered DNA-binding molecule-mediated chromatin immunoprecipitation (enChIP). Sci. Rep. 3, 3171 (2013).

16. Fujita, T., \& Fujii, H. Identification of proteins associated with an IFNy-responsive promoter by a retroviral expression system for enChIP using CRISPR. PLoS One. 9, e103084 (2014).

17. Fujita, T., Yuno, M., Okuzaki, D., Ohki, R., \& Fujii, H. Identification of non-coding RNAs associated with telomeres using a combination of enChIP and RNA sequencing. PLoS One. 10, e0123387 (2015).

18. Naito, Y., Hino, K., Bono, H., \& Ui-Tei, K. CRISPRdirect: software for designing CRISPR/Cas guide RNA with reduced off-target sites. Bioinformatics. (2014).

19. Mali, P. et al. RNA-guided human genome engineering via Cas9. Science. 339, 823-826 (2013).

20. Esvelt, K. M. et al. Orthogonal Cas9 proteins for RNA-guided gene regulation and editing. Nat. Methods. 10, 1116-1121 (2013).

21. Qi, L. S. et al. Repurposing CRISPR as an RNA-guided platform for sequence-specific control of gene expression. Cell. 152, 1173-1183 (2013).

22. Wu, X. et al. Genome-wide binding of the CRISPR endonuclease Cas9 in mammalian cells. Nat. Biotechnol. 32, 670-676 (2014).

23. Kuscu, C., Arslan, S., Singh, R., Thorpe, J., \& Adli, M. Genome-wide analysis reveals characteristics of off-target sites bound by the Cas 9 endonuclease. Nat Biotechnol. 32, 677-683 (2014).

24. Cencic, R. et al. Protospacer adjacent motif (PAM)-distal sequences engage CRISPR Cas9 DNA target cleavage. PLoS One. 9, e109213 (2014).

25. O'Green, H., Henry, I. M., Bhakta, M. S., Meckler, J. F., \& Segal, D. J. A genome-wide analysis of Cas9 binding specificity using ChIP-seq and targeted sequence capture. Nucleic Acids Res. 43, 3389-3404 (2015).

26. de Lange, T. Shelterin: the protein complex that shapes and safeguards human telomeres. Genes Dev. 19, $2100-2110$ (2005). 